is the chief result of the Scotch Commission and the many further inquiries set going by it. Physical training has shared in the benefits of more scientific direction. The rest of the history is written in the statutes and administrative orders and circulars now current in Great Britain. A movement so wide and so costly could have emerged only from a great national awakening, and this report, the first of the new medical department, shows how far advanced the organisation already is. The report contains all the administrative detail necessary to enable the interested sociologist to grasp the significance of the movement.

Naturally, in a first report, questions of organisation and administration bulk relatively large. Dr. Newman makes very clear the relation of the new school medical officers to the public health service. This was a matter of great concern at the outset, but the solution of difficulties seems to have gone forward smoothly, and to-day any dissociation of services is the exception, not the rule. Subordination of the school medical officer to the medical officer of health, or some definite form of cooperation, seems to have been established practically in every educational area. "There is an interdependence and solidarity in these matters which can only be ignored or neglected at the price of inefficiency and failure " $(\mathrm{p}, 17)$

Whole-time medical assistants are the rule, part-time assistants the exception. "There have been no cases of Authorities commencing with a few whole-time assistants and changing to many part-time assistants" (p. rg). This is a very significant fact. Of the 307 educational areas, 160 have been provided with one school medical officer each-the minimum necessary under the Code. In the other 147 areas, "there are in all 616 assistant medical officers "-122 whole-time, 494 part-time. The arrangements for twenty-one other areas have not yet been finally approved, but, approximately, 1084 medical officers are at work "in the school medical service in England and Wales" (p. 18). This is certainly a splendid record. The qualifications of officers, the part played by the teacher, the school nurse, the general scope of the work, all are discussed with quantitative references. It is estimated that, for England and Wales, not fewer than $1,328,000$ children were medically inspected during $1907-8$, and when to these are added 250,000 "specials," that is, children specially brought under the medical inspector's notice as needing attention, the total amounts to not less than I $\frac{3}{2}$ million children. The general experience with parents is that they have appreciated the work warmly, and sometimes enthusiastically, there being a few, but only a few, complainers.

As to treatment, the facts are, of course, very meagre as yet, but not discourasing. So far as facts are available, the number medically attended to through the parents themselves runs from 20 to 60 per cent. of those brought to their notice by the education authorities. There is here abundant room for organisation and propaganda. The cost of medical inspection, so far as salaries go, runs from $4.79 d$. per child in average attendance in the counties to $7 \cdot 64 d$ in the municipal boroughs and $7.56 \mathrm{~d}$. in the urban districts, or, in the same order, from o.I 5 d. of rate to $0.23 d$. and $0.28 d$. - no great outlay for so great a service.

The rest of the volume is taken up with details of the results of medical inspection in the discovery of defects or diseases. The results are necessarily "tentative and fragmentary" (p. 39), but more than enough to justify the institution of the system and to indicate the immense amount of administrative energy now directed to the amelioration of evil conditions, both environmental and personal. Cleanliness is steadily improving under the pressure of definite administrative direction. For instance, in 124 London schools Dr. Kerr found, of 92,185 children examined, $\mathbf{1 6} 6,060$ verminous, and $\mathbf{2 2 2 8}$ were excluded for prosecution-the parents of 255 children being prosecuted, and fined in sums varying from $1 s$. $6 d$. to $20 s$. As a rule, the first " notice" is enough to secure cleansing. Ringworm is diminishing. Teeth are beginning to be treated, as, for instance, in Cambridge. Many other diseases now familiar to the general public are here recorded-adenoidal growths, ear discharges, short sight, \&c. There is a good series of paragraphs dealing with tuberculosis, in particular with phthisis. The results in percentages for phthisis vary widely-from well below I to well above 4. Obviously there are differences both in the localities and in the methods of diagnosis. This is a disease that has not yet found its "level" in the professional mind. There are sections dealing with the new syllabus of hygiene, with schools for defective children, open-air schools, and many other matters of current importance.

The report, as a whole, refiects every credit on the system of medical inspection and on the Board of Education itself. Only the experienced administrator can read from these records the enormous difficulties to be overcome and the skill shown in overcoming them.

\section{NOTES ON THE ORIGIN OF THE HAUSAS.}

$\mathrm{NEXT}$ to the Filani, the most important race in northern Nigeria is the Hausa, whose origin is undetermined. These people occupy at present most of the land between the ninth and fourteenth parailels north latitude, and the fourteenth and eleventh meridians east longitude. Their number is variously estimated; perhaps $4,000,000$ is fairly accurate. They are the traders and soldiers of West Africa, and are very good agriculturists, and workers in brass and leather, but seem to have been unable to conquer under their own leaders.

The Hausas have not the fine features of the Filani, nor yet the very thick lips and flat noses of the coast negro; they are rather short and stumpy, with woolly hair. Their original country in northern Nigeria consisted of seven States, the "Hausa Bokkoi," to which an equal number, "Banza Bokkoi," were afterwards added. These States were independent of-though dependent on-one another. There are two principal theories as to their origin, viz. (I) that they were indigenous, and (2) that they came from Egypt or Ethiopia. I cannot see why these two apparently opposite ideas cannot be modified and reconciled.

It would seem that the following statements are permissible :-

(r) The religion is in too many points similar to that of the ancient Egyptians to imagine that it was formed quite independently.

(2) The Hausas have the trading and wandering instincts of the Semites, and have travelled voluntarily and without external pressure, whereas the people of most West African negro tribes have kept together, unless conquered and driven out of their country.

(3) The cephalic index is one which we would naturally expect in the descendants of a mixture of races, some having a sreater, some a less, index. Because the Arabic element was in the minority, and because of the influence of environment, the Hausa cephalic index is nearer to that of the Egyptian Copts and mixed races than to that of the Arabs. The present Hausa race is a further mix ture of the people who came, in A.D. rooo, with the aborigines.

(4) Arabic has had some influence in the formation of the Hausa grammar, as well as supplying about one-third of the words, and so some of the people who formed the Hausa rocabulary nust have known Arabic. Again, since two-thirds of the words present no similarity to any Semitic language, it is evident that other elements are present, and some of these are related to Coptic. The word Habeshi was a term of contempt applied by Arabs to inixed races, and Hausa (Ba-haushe) is a modification.

(5) The people came from the East (ancient Ethiopia) and brought the horse. Arabs had horses at this time (I000 A.D.), and the mixture which arrived no doubt spoke a certain amount of Arabic. They may have been Hamites, but it is much more likely that they were a mixture of Hamites and Semites, together with elements of local populations encountered en route, and the original inhabitants of the country now forming the Hausa States. There is probably a little Berber blood also, and even a further addition of Arabic. Being ashamed of their humble origin, they invented one for themselves, and called their mythical ancestor Babushe, which is really $\mathrm{Ba}-($ ha)beshi and $\mathrm{Ba}-\mathrm{hab}(\mathrm{e})$ shi or $\mathrm{Ba}$-haushe.

1 From a paper by Capt. A. J. N. Treme-rze in the Journal o' the Royal Society of Arts, July 8

Nก๊. 2 I 24 , VOL. 84] 